\title{
Reliability and accuracy of a radiographic analysis method for posterior maxillary mini-implant location
}

Luís Carlos Sampaio DIAS ${ }^{1}$, Yomara Barreto da Costa FERREIRA ${ }^{2}$, Rudys Rodolfo de JESUS TAVAREZ ${ }^{3}$, Célia Regina Maio PINZAN-VERCELINO ${ }^{3}$, Júlio de Araújo GURGEL ${ }^{4}$

\author{
1- DDS, MSc, Graduate student in Orthodontics, University Center of Maranhão - UNICEUMA, São Luis, MA, Brazil. \\ 2- Undergraduate student, Dental School, University Center of Maranhão - UNICEUMA, São Luis, MA, Brazil. \\ 3- DDS, MSc, PhD, Professor of Master's Degree Program in Dentistry, University Center of Maranhão - UNICEUMA, São Luis, MA, Brazil. \\ 4- DDS, MSc, PhD, Professor and Coordinator of the Master's Degree Program in Dentistry, University Center of Maranhão - UNICEUMA, São Luis, MA, Brazil.
}

Corresponding address: Dr. Júlio de Araújo Gurgel - R. Cel José Braz, 480 - Centro - Marília - SP - 17501-570 - Brazil - Phone/Fax: $55143413-5321$ e-mail: jagurgel@terra.com.br

Received: December 02, 2009 - Modification: May 10, 2010 - Accepted: October 26, 2009

\section{ABSTRACT}

\begin{abstract}
$\mathrm{O}$ bjective: The purpose of this study was to evaluate the reliability and accuracy of a radiographic analysis method for the location of mini-implants inserted in the posterior region of the maxilla. Material and Methods: Two self-drilling mini-implants were installed between the second premolar and the first molar on the right side and left side in three dry skulls. Three operators performed three occlusal radiographs, using an occlusal $x$-ray film holder, at three different times in each of the three skulls. Results: The interclass correlation coefficient showed a significantly high, positive correlation $(p<0.05)$, indicating an excellent reliability between operators. The analysis of variance showed no significant differences in time and among the operators. Conclusion: Based of these findings, it may be concluded that this methodology can be used by several operators in longitudinal clinical studies on orthodontic mini-implants at the anterior-posterior and lateral-medial locations or longitudinal displacement.
\end{abstract}

Key words: Dental implants. Radiographic film. Orthodontic anchorage procedures.

\section{INTRODUCTION}

Orthodontic anchorage is a basic procedure necessary for a successful treatment. For this reason, clinicians seek to better understand various orthodontic devices, such as headgear, transpalatal arch, lingual arch, and Nance's button. These devices allow a certain degree of movement of the anchorage unit and are dependent, to varying degrees, on patient compliance. In severe cases or in cases of non-cooperative patients, treatment could be compromised. Recently, skeletal anchorage has increased in popularity due to the benefit of direct transfer of the point of anchorage from the teeth to the skeleton ${ }^{6,9,10}$. However, since these miniimplants have been used in orthodontics, a small displacement during treatment has been detected. The mini-implant displacement allows contact between the screw and the dental root, causing damage to the root or the periodontal ligament, potentially leading to mobility or loss of the miniimplant $3,11,12,15,16,17,18$.

Unfortunately, there is not much information available on the displacement or adverse effects of mini-implants. Recently, Hsieh, et al. ${ }^{8}$ (2008) found that even endosseous titanium implants may not necessarily serve as a rigid orthodontic anchorage at all force levels. Lateral films no longer provide the best images to study such small devices. Liou, et al. ${ }^{13}$ (2004) investigated cephalometric tracings and found a noteworthy extrusion and tipping forward of mini-implants after en-masse retraction of anterior teeth. Recently, tomographic studies have evaluated the position of mini-implants in both jaws, though without relating them to longitudinal control ${ }^{1,14}$. To the best of our knowledge, no tomographic study had quantified mini-implant displacement in orthodontic patients. 
General dentistry and orthodontics constantly use radiographs with the main purpose of assessing the validity of treatment methods. Zanda ${ }^{20}$ (2007) described a new film holder for occlusal film that showed effective reproducibility of occlusal radiographic images in dry skulls (Figure 1 ), making it possible to take an occlusal radiographic sequence at different times. Gurgel, et al. ${ }^{16}$ (2005) used dry human skulls to analyze the reliability in determining tooth position in posterior-anterior films. Using markers inserted in the bands of molars and premolars from Hyrax expanders allow identifying each one in each side on posterior-anterior films.

The purpose of the present study was to evaluate the reliability and accuracy of a radiographic analysis method for identifying the location of mini-implants inserted in the posterior region of the maxilla in dry human skulls.

\section{MATERIAL AND METHODS}

Three human skulls were obtained from the Anatomy Department of the Dental School of the University Center of Maranhão, Brazil. All skulls had preserved maxilla and mandible and sufficient teeth on the posterior area of the maxilla for the successful placement of mini-implants. The cortical bone condition and the maxillary interadicular space were evaluated using radiographic images between the second premolars and the first molars. According to the same technical criteria used for patients, six self-drilling mini-implants $(1.6 \times 1 \times 7 \mathrm{~mm}$; OSAS, DEWIMED, Tuttlingen, Germany) were placed between the second premolars and the first molars at a $45^{\circ}$ angle relative to the tooth's long axis.

Once the study began, the main purpose was to test the reliability of different operators for the proposed method in this research. Therefore, clinical operators with various levels of professional experience were invited to take the occlusal radiographs. Three operators were selected: an orthodontist, an implantodontist and an undergraduate dental student. Each operator performed three occlusal radiographs taken at three intervals of 15 days in each of the three skulls. The set of three radiographs of each skull was identified externally according to an identification number for the skull, the operator and the time.

A total of 27 randomized occlusal radiographs were obtained using insight IO-41 film (size 5.7 $\mathrm{cm} \times 7.6 \mathrm{~cm}$; KODAK) with $1.5 \mathrm{~s}$ exposure time at $10 \mathrm{~mA}$ and $70 \mathrm{kV}$. The occlusal radiographs were taken with a correct alignment between the cylinder localizer from the $x$-ray machine and the ring from the occlusal radiographic position self-drilling film. Each operator took the occlusal radiograph for each of the skulls with the occlusal films inserted in the Zanda $^{20}$ (2007) film holder and fit the film in more

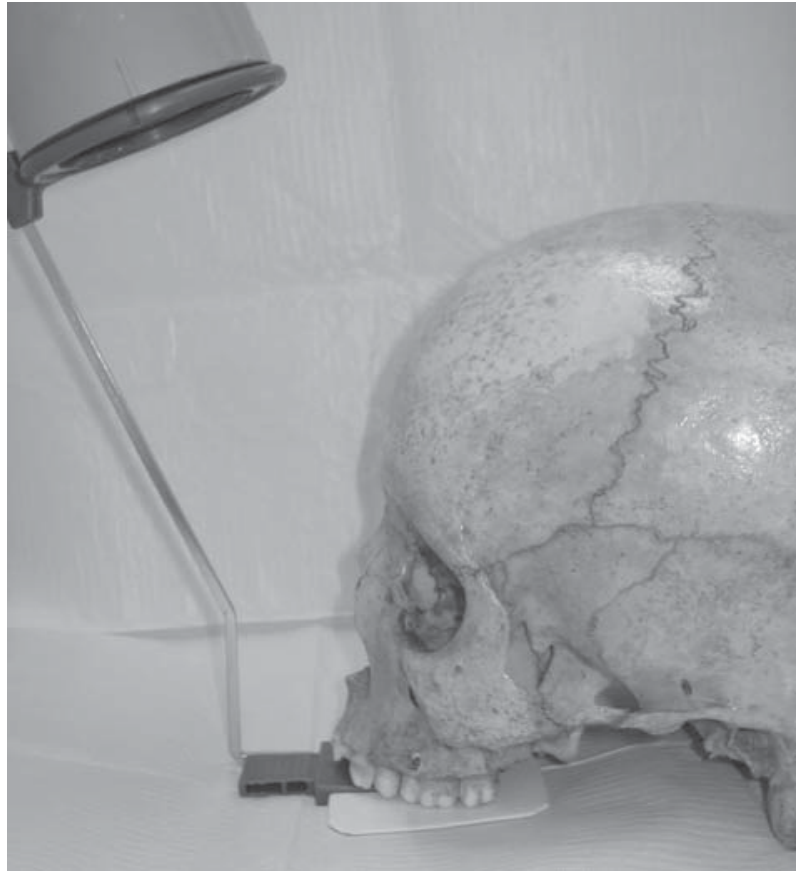

Figure 1- Occlusal x-ray film holder and skull positioned for standardized occlusal radiograph

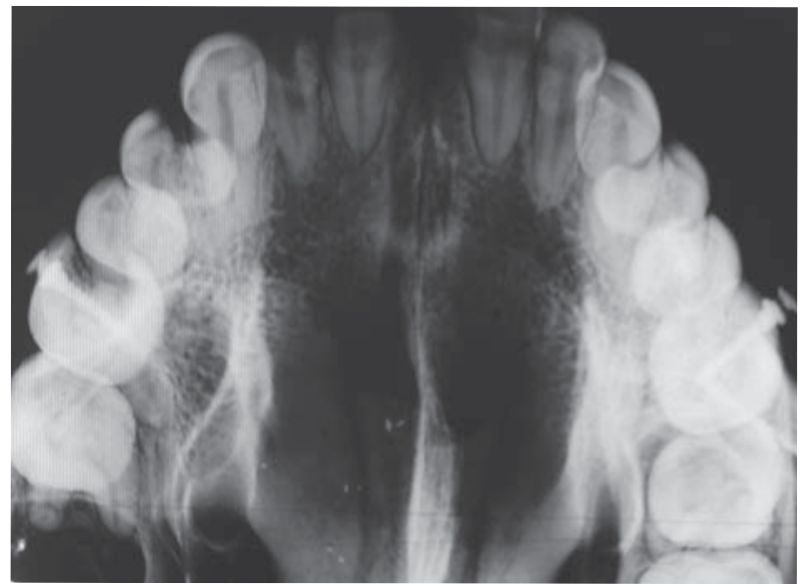

Figure 2- Occlusal radiographs with mini-implants placed

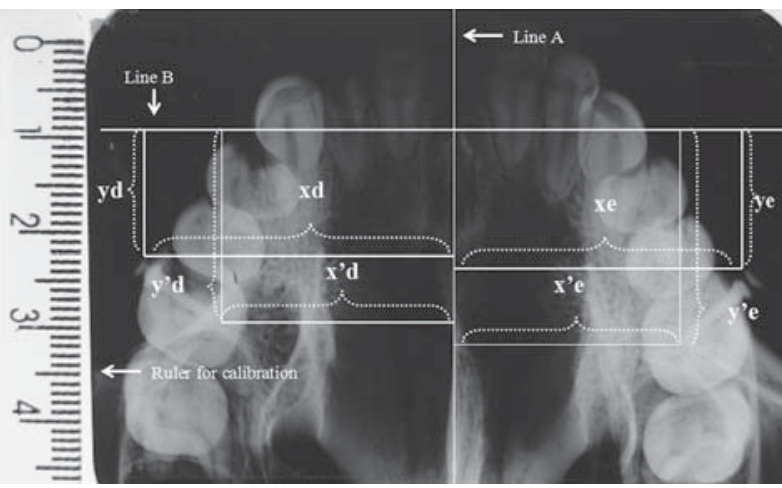

Figure 3- Occlusal radiographs and measurements 
Table 1- Mean and standard deviation (SD) for each measurement and operator (OP)

\begin{tabular}{|c|c|c|c|c|c|c|c|c|}
\hline & & & \multicolumn{2}{|c|}{ OP1 } & \multicolumn{2}{|c|}{ OP2 } & \multicolumn{2}{|c|}{ OP3 } \\
\hline & & & Mean & SD & Mean & SD & Mean & SD \\
\hline \multirow[t]{8}{*}{ Skull 1} & Left & $x$ & 32.43 & 0.50 & 32.77 & 0.07 & 32.25 & 0.30 \\
\hline & & $y$ & 13.49 & 0.28 & 13.37 & 0.24 & 13.68 & 0.57 \\
\hline & & $x^{\prime}$ & 24.32 & 0.31 & 25.19 & 0.27 & 24.50 & 0.20 \\
\hline & & $y^{\prime}$ & 20.53 & 0.26 & 20.43 & 0.27 & 20.65 & 0.50 \\
\hline & Right & $x$ & 31.83 & 0.34 & 31.36 & 0.34 & 31.36 & 0.11 \\
\hline & & $y$ & 13.17 & 0.83 & 13.61 & 0.44 & 12.87 & 0.81 \\
\hline & & $x^{\prime}$ & 24.60 & 0.39 & 24.65 & 0.33 & 24.85 & 0.30 \\
\hline & & $y^{\prime}$ & 21.68 & 0.65 & 21.96 & 0.32 & 21.33 & 0.69 \\
\hline \multirow[t]{8}{*}{ Skull 2} & Left & $x$ & 30.06 & 0.45 & 30.25 & 0.66 & 31.04 & 0.30 \\
\hline & & $y$ & 2.70 & 0.17 & 2.98 & 0.47 & 2.51 & 0.27 \\
\hline & & $x^{\prime}$ & 21.62 & 0.52 & 21.81 & 0.51 & 22.40 & 0.41 \\
\hline & & $y^{\prime}$ & 9.49 & 0.26 & 9.41 & 0.45 & 9.34 & 0.24 \\
\hline & Right & $x$ & 27.66 & 0.59 & 27.87 & 0.88 & 28.19 & 0.92 \\
\hline & & $y$ & 5.63 & 0.20 & 5.72 & 0.31 & 5.73 & 0.56 \\
\hline & & $x^{\prime}$ & 18.27 & 0.45 & 18.46 & 0.58 & 18.71 & 0.69 \\
\hline & & $y^{\prime}$ & 11.57 & 0.12 & 11.55 & 0.41 & 11.81 & 0.39 \\
\hline \multirow[t]{8}{*}{ Skull 3} & Left & $x$ & 31.21 & 0.43 & 31.02 & 0.71 & 31.57 & 0.68 \\
\hline & & $y$ & 7.74 & 0.39 & 7.86 & 0.10 & 8.25 & 0.08 \\
\hline & & $x^{\prime}$ & 23.69 & 0.48 & 23.61 & 0.53 & 23.72 & 0.53 \\
\hline & & $y^{\prime}$ & 15.81 & 0.30 & 15.92 & 0.13 & 16.43 & 0.33 \\
\hline & Right & $x$ & 28.86 & 0.59 & 29.03 & 1.20 & 29.54 & 0.93 \\
\hline & & $y$ & 7.53 & 0.67 & 7.50 & 0.22 & 7.60 & 0.63 \\
\hline & & $x^{\prime}$ & 20.39 & 0.41 & 20.48 & 0.62 & 20.92 & 0.72 \\
\hline & & $y^{\prime}$ & 13.11 & 0.40 & 13.34 & 0.21 & 13.54 & 0.91 \\
\hline
\end{tabular}

number of posterior teeth of the maxilla.

All radiographs and a ruler with same lateral size were digitized using a scanner (Be@rPaw 2400TA Plus, Scanner A4) (Figure 2). The radiographs were measured using MacBiophotonics Image] software originally applied in biologic researches for microscopic image capture. Two ruler points were initially defined for calibration. After the mini-implant positions, the points were defined and measured using a Cartesian coordinate system (Figure 3). The Cartesian system was composed by the following measures:

Line A: a straight line traced over the maximum number point of the midpalatal suture;

Line $B$ : a line perpendicular to the intersection of line $A$ at the virtual point representative of the incisive foramen;

Distance $x d$ : for the mini-implant on the right side, the minimum distance from the head of the mini-implant to line $A$;

Distance yd: for the mini-implant on the right side, the minimum distance from the head of the mini-implant to line $B$;

Distance $x^{\prime} d$ : for the mini-implant on the right side, the minimum distance from the tip of the miniimplant to line $A$;

Distance $y^{\prime} d$ : for the mini-implant on the right side, the minimum distance from the tip of the miniimplant to line B;
Distance xe: for the mini-implant on the left side, the minimum distance from the head of the mini-implant to line $A$;

Distance ye: for the mini-implant on the left side, the minimum distance from the head of the mini-implant to line $B$;

Distance $x^{\prime}$ e: for the mini-implant on the left side, the minimum distance from the tip of the mini-implant to line $A$;

Distance $y^{\prime}$ e: for the mini-implant on the left side, the minimum distance from the tip of the mini-implant to line $B$.

The means and standard deviations of the distances on each side were calculated considering the operator and the skull (Table 1). The intraoperator reliability for the measurements was estimated using the interclass correlation coefficient (ICC). Analysis of variance (ANOVA) was used to test the effect of different image times and different operators.

\section{RESULTS}

Statistical analysis indicated a significantly high, positive correlation between the maxillary occlusal radiography taken by the different operators (Table 2 ). These data indicate an excellent reliability between operators.

The ICC test verified the measurements of each 
Table 2- Intra-operator reliability for mini-implant measurements expressed as interclass correlation coefficient (ICC) $(n=3)$

\begin{tabular}{cccc}
\hline Variable & $\mathbf{r}$ & $\mathbf{P}$ & Significance \\
\hline $\mathrm{x}$ & 0.8778 & $<0.05$ & NS \\
$\mathrm{y}$ & 0.9848 & $<0.05$ & NS \\
$\mathrm{x}^{\prime}$ & 0.9608 & $<0.05$ & NS \\
$\mathrm{y}^{\prime}$ & 0.9920 & $<0.05$ & NS \\
\hline
\end{tabular}

$\mathrm{NS}=$ not significant

Table 3- ANOVA for measurements of $x, y, x^{\prime}$ and $y^{\prime}$

\begin{tabular}{cccc}
\hline variable & $\begin{array}{c}\text { ANOVA } \\
\text { operator } \mathbf{p}\end{array}$ & $\begin{array}{c}\text { ANOVA } \\
\text { time } \mathbf{p}\end{array}$ & $\begin{array}{c}\text { ANOVA } \\
\text { time and } \\
\text { operator } \mathbf{p}\end{array}$ \\
\hline $\mathrm{x}$ & 0.672 & 0.909 & 0.993 \\
$\mathrm{y}$ & 0.993 & 0.972 & 1.000 \\
$\mathrm{x}^{\prime}$ & 0.904 & 0.927 & 0.999 \\
$\mathrm{y}^{\prime}$ & 0.986 & 0.981 & 1.000 \\
\hline
\end{tabular}

variable made by each operator on each skull that localize the head and the tip of the mini-implant ( $x$, $y, x^{\prime}$ and $\left.y^{\prime}\right)$. Intra-operator correlations were above 0.87 for all the operators and each of the skulls (Table 2). This value seems to indicate a similar variation, indicating an excellent reproducibility through a positive and high correlation.

In terms of the effect of time, the operator and its interactions showed no statistically significant differences in any of the variables analyzed by ANOVA (Table 3).

\section{DISCUSSION}

The goal of the present study was to test the reliability and accuracy of the radiographic occlusal position developed by Zanda ${ }^{20}$ (2007) used as a device to verify the stability of posteroanteriorly and lateromedially positioned orthodontic mini-implants. The hypothesis was that this method can be used as a replicate for maxillary occlusal radiographs for location of mini-implant placement in the posterior region of the maxilla.

Since the introduction of the cephalostat as a standard for taking cephalometric radiographs, the cephalostat has been traditionally used to determine the direction and amount of skeletal and dental changes. Several devices have also been developed and improved with longitudinal research in orthodontic patients. Some studies have reported that film holders and markers of anatomic structures contribute to the improvement in radiographic images. Also creating more information about the position of structures during orthodontic treatments ${ }^{5,7}$. Based on these presumptions, our study used a model of an occlusal x-ray film holder to obtain the most uniform radiographic series. Additionally, the selected anatomic structures used as references to determinate the measurements were chosen because they are known to be stable during treatment.

This study showed that the use of the occlusal $x$-ray film holder is sufficiently accurate for investigations of mini-implant stability and an alternative to cephalometric analyses for determinate mini-implant displacement. Furthermore, the numerical information on the displacement of the mini-implants can be correlated with the amount of dental movement determined by the retraction. Liou, et al. ${ }^{13}$ (2004) reported that mini-implants do not remain stable at forces higher than $400 \mathrm{~g}$. These findings suggest that studies are necessary to quantify mini-implant displacement caused by treatment, especially by means of the innumerable variables related to the use of this transitional anchorage device.

Our findings show that future clinical studies will be able to evaluate the direction of the displacement of the mini-implants. Also, different types of this skeletal anchorage device could be compared considering the thickness, the design and the length with the suffered displacement.

Computed tomography (CT) scans are not routinely used to improve the quality of craniofacial measurements in orthodontics. The present data prove that the method presented here is valid and can be performed at a much lower cost compared to CT. This means that clinicians and researchers can better understand this innovative modality of anchorage using an easily attainable and low-cost material. Another important benefit of this method is a lower exposure of patients to radiation to detect the stability of the mini-implants. We believe that clinical studies on this topic are very important for further acknowledgment of transitory anchorage device. However, there is a great deal of responsibility in deciding to prescribe radiographs, especially CT scans; it is complicated and depends on the effects on the orthodontic therapy management ${ }^{19}$.

Human skulls were used for safety reasons due to the potential exposure of patients to ionizing radiation. The adopted model simulates similar conditions used for patients, with a reduced $x$-ray exposure time 4 . Additionally, the anatomic structures used to obtain all measurement tracings are easily identified, as well as their presence in the same plane and height as the indicated inserted mini-implant in the posterior maxillary area. Here we used dry skulls. For future studies in patients, we believe that the selected areas are not influenced by soft tissue thickness and do not compromise the visualization of the anatomic structures used and 
the installed mini-implants.

The number of dry skulls used in this type of study has revealed variations in other studies ${ }^{1,7,14}$. These differences are probably due to the number of measurements analyzed. The number of skulls used in the present study was sufficient to verify the influence of individual anatomic variations in the statistical analysis. It should be noted that we opted for a research design that did not evaluate the anatomic aspects in relation to accuracy and reliability ${ }^{2}$. The aim of the study was to analyze operator's reproducibility on separate occasions. The intraclass correlation proved that, with the skull change and, consequently, the occurrence of anatomic variations, a high and significant correlation was found among the different measurements of each skull. These data indicate an excellent reproducibility between the operators. The agreement in the operators' measurements (Table 3 ) shows that this method is useful for research and for clinical evaluation. For clinical use, it is indicated to attach the film to the film holder (Figure 1) and after adaption inside of the mouth, ask for the patient to occlude. Only with the dental occlusion is possible to achieve stability to use this intraoral radiographic technique.

Zanda $^{20}$ (2007) found variations in the reliability of measurements far from the occlusal plane, whereas the present study showed no statistically significant differences. In the present study, this reproducibility was found because the mini-implants and the anatomic structures used the same plane into the maxilla, both are at the same tall of palatal plane. Variables describing the position of the head and the tip of the mini-implant were in the same plane. Also, the midpalatal suture was chosen as a reliable reference for the determination of a measurement for each variable. It should be mentioned that the method presented here only identifies mini-implant localization on the posterior region of the maxilla. This implies that, in future studies, an additional use for this method in another site of the maxilla or mandible may be the identification of a more reliable anatomic structure for each studied region.

\section{CONCLUSIONS}

The results of the present study demonstrate that this radiographic method was highly reproducible among operators and accurate for the identification of measurements. Also, no differences were observed based on the time and the operator using this method. These results support the use of this standardized method for occlusal radiographs for mini-implant identification on the posterior maxilla.

\section{REFERENCES}

1- Baumgaertel S, Palomo JM, Palomo L, Hans MG. Reliability and accuracy of cone-bean computed tomographiy dental measurements. Am J Orthod Dentofacial Orthop. 2009;136:19-28. 2- Berco M, Rigali PH Jr, Miner RM, DeLuca S, Anderson, NK, Will LA. Accuracy and reliability of linear cephalometric measurements from cone-beam computed tomography scans of a dry human skull. Am J Orthod Dentofacial Orthop. 2009;136:17-8.

3- Berens A, Wiechmann D, Dempf R. Mini- and micro-screws for temporary skeletal anchorage in orthodontic therapy. J Orofac Orthop. 2006;67:450-8.

4- Brazil. Ministry of Health. National Health Surveillance Agency. Publication 453 of June 1st, 1998. Diretrizes de proteção radiológica em radiodiagnóstico médico e odontológico. Federal Official Gazette of Brazil. Brasília (1998 Jun 2).

5- Byloff FK, Mossaz CF. Skeletal and dental changes following surgically assisted rapid palatal expansion. Eur J Orthod. 2004,26:403-9.

6- Cornelis MA, Scheffler NR, De Clerck HJ, Tulloch JF, Behets CN. Experimental systematic review of the uses of temporary skeletal anchorage devices in orthodontics. Am J Orthod Dentofacial Orthop. 2007; 131:S52-8.

7- Gurgel JA, Sant'ana E, Ferreira Júnior O, Sant'ana LFM, Giglio FPM. O uso de marcadores para identificação de posicionamento dentário em telerradiografias frontais póster-anteriores: proposta de um método. Rev Dent Press Ort Ortop Facial. 2005;10:84-90. 8- Hsieh YD, Su CM, Yang YH, Fu E, Chen HL, Kung S. Evaluation on the movement of endosseous titanium implants under continuous orthodontic forces: an experimental study in the dog. Clin Oral Implants Res. 2008;19:618-23.

9- Kanomi R. Mini-implant for orthodontic anchorage. J Clin Orthod. 1997;31:763-7.

10- Kuroda S, Sugawara Y, Deguchi T, Kyung HM, TakanoYamamoto T. Clinical use of miniscrew implants as orthodontic anchorage: success rates and postoperative discomfort. Am J Orthod Dentofacial Orthop. 2007;131:9-15.

11- Kuroda S, Yamada K, Deguchi T, Hashimoto T, Kyung HM, Yamamoto T. Root proximity is a major factor for screw failure in orthodontic anchorage. Am J Orthod Dentofacial Orthop. 2007;131:S68-73.

12- Lee JS, Park HS, Kyung HM. Micro-implant anchorage for lingual treatment of a skeletal Class II malocclusion. J Clin Orthod. 2001;35:643-7.

13- Liou EJ, Father BC, Lin JC. Do miniscrews remain stationary under orthodontic forces? Am J Orthod Dentofacial Orthop. 2004; $126: 42-7$.

14- Monnerat C, Restle L, Mucha JN. Tomographic mapping of mandibular interradicular spaces for placement of orthodontic miniimplants. Am J Orthod Dentofacial Orthop. 2009;135:428.e1-e9. 15- Park HS. The skeletal cortical anchorage using titanium microscrew implants, Kor J Orthod. 1999;29:699-706.

16- Park HS, Bae SM, Kyung HM, Sung JH. Micro-implant anchorage for treatment of skeletal Class I bialveolar protrusion. J Clin Orthod. 2001;35:417-22.

17- Park, HS, Jeong SH, Kwon OW. Factors affecting the clinical success of screw implants used as orthodontic anchorage. Am J Orthod Dentofacial Orthop. 2006;130:18-25.

18- Romanos GE, Toh CG, Siar CH, Swaminathan D. Histologic and histomorphometric evaluation of peri-implant bone subjected to immediate loading: and experimental study with Macaca fascicularis. Int J Oral Maxillofac Implants. 2002;17:44-51.

19- Turpin DL. British Orthodontic Society revises guidelines for clinical radiography. Am J Orthod Dentofacial Orthop. 2008;134:597-8.

20- Zanda MJ, Vidotti BA, Capelozza, ALA. Development of a film-holding instrument to obtain occlusal radiographs. Revista APCD. 2007;61:55-60. 